\title{
POTENCIAL DE CAPTAÇÃO DE ÁGUA DE CHUVA PELAS FACHADAS PARA USO NÃO POTÁVEL
}

\author{
Cristina Toca Pérez ${ }^{1}$; Rodrigo Brito ${ }^{2}$ \\ ${ }^{1}$ SENAI-CIMATEC, Av. Orlando Gomes 1845, Piatã-Salvador/Bahia; \\ cristina.perez@fieb.org.br \\ ${ }^{2}$ SENAI-CIMATEC, Av. Orlando Gomes 1845, Piatã-Salvador/Bahia
}

Resumo: O presente estudo avaliou o potencial de captação de águas pluviais pelas fachadas de edificações. Para tal, foi estudado um empreendimento residencial vertical de quatro pavimentos com uma área de $900 \mathrm{~m}^{2}$ de fachada. $\mathrm{O}$ cálculo dos valores do Volume Captado (diário e mensal), bem como da Taxa de Atendimento (mensal e diária) foram estudados para os dois tipos mais comuns de revestimentos de fachada encontrados na cidade de Salvador/BA, os argamassados com pintura e os cerâmicos, tendo os dois tipos, apresentado bons resultados quanto aos volumes captados. Os resultados mostram que, a captação de água de chuva para utilização em fins não potáveis se mostrou oportuna, visto que a fachada possui área de captação significativa para suprir a demanda deste tipo de água, nos meses mais secos e pode servir para fins de armazenagem, nos meses mais chuvosos

Palavras-Chave: Fachada; Captação de água de chuva; Revestimentos.

\section{POTENTIAL FOR COLLECTING RAINWATER THROUGH BUILDING FAÇADES FOR NON-POTABLE PURPOSES}

\begin{abstract}
The present study evaluated the potential for collecting rainwater through building façades. For that, a vertical residential project of four floors with an area of $900 \mathrm{~m}^{2}$ of facade was studied. The calculations of the Capture Volume (daily and monthly), as well as the Attendance Rate (monthly and daily) were studied for the two most common types of facade coverings found in the city of Salvador/BA, mortar with paint and ceramics, both types have good results in terms of volumes collected. The results show that rainwater harvesting for non-potable purposes was timely, since the façade has a significant catchment area to meet the demand for this type of water in the driest months and can be used for storage purposes, in the rainiest months.
\end{abstract}

Keywords: Facades; Rainwater harvesting; Coverings. 


\section{INTRODUÇÃO}

A escassez de água apresenta-se como um dos grandes desafios atuais. $O$ Brasil, mesmo apresentando uma das maiores bacias hídricas do mundo, possui em suas regiões, diversas zonas de escassez de água potável ocasionada pela inexistência de um equilíbrio entre a distribuição populacional, industrial e agrícola [1]. O contínuo aumento da população, o adensamento das cidades e a mudança na cobertura vegetal, configuram a atual evolução urbana em escala global nas últimas décadas. Como consequência, intensificaram-se as atividades dos diversos setores da construção civil, o que desencadeia numa redução da infiltração das águas pluviais no solo, ocasionada pelo aumento das áreas impermeáveis [2]

Os grandes centros urbanos por sua vez, sofrem impactos sociais, econômicos e ambientais negativos resultantes de eventos hidrológicos. A impermeabilização do solo provoca a ocorrência de enchentes e inundações afetando grande parte da população. Além disso, a redução da infiltração das águas no solo suscita a necessidade de uma maior capacidade de captação destas águas por parte do sistema público em um menor tempo [3]. Neste cenário, a captação direta de águas pluviais nas edificações pode ser tratada como uma forma para a diminuição dos problemas decorrentes das enchentes e inundações, e pode permitir a redução da demanda de captação por parte do sistema público [3].

No Brasil, a captação da água pluvial é orientada pela NBR 15527:2007 - Água de Chuva - Aproveitamento de Coberturas em Áreas Urbanas Para Fins Não Potáveis. A norma especifica a utilização das águas captadas apenas para fins não potáveis, tais como: irrigação de jardins, uso em descargas sanitárias e lavagens de pisos. Nesta, também podem ser encontrados os principais direcionamentos quanto as referências técnicas, equipamentos e manutenção, além de informações acerca da qualidade final da água.

No entanto, é importante destacar que a NBR 15527 rege apenas a captação da chuva sobre os telhados, não abordando a captação das águas pluviais que escorrem em outros sistemas como fachadas, garagens abertas, playgrounds descobertos e quadras esportivas [4]. Esses locais, ainda não normatizados, necessitam de uma maior atenção em relação ao tratamento da água e seus sistemas específicos, pois representam parcelas significativas das águas que escorrem em uma edificação, aumentando o volume captado que poderá ser destinado a mais usos. Desta forma, através do presente estudo, buscou-se avaliar o potencial de captação de águas pluviais pelas fachadas de um edifício, a fim de entender as principais características que envolvem este tipo de captação.

\section{REVISÃO DA LITERATURA}

A NBR 15527 - Água de chuva: aproveitamento de coberturas em áreas urbanas para fins não potáveis, que entrou em vigor desde final de outubro de 2007, norteia a elaboração e adoção deste sistema, mencionando as circunstâncias e destinações para quais as águas pluviais podem ser utilizadas, levando-se em 
consideração o adequado tratamento. Alguns dos exemplos de uso mencionado pela norma é a utilização em descargas de vasos sanitárias, irrigação de gramados e plantas ornamentais, lavagem de veículos, limpeza de calçadas e ruas, limpeza de pátios, espelhos d'água, etc.

\subsection{Superfície de Captação da água de chuva}

A captação de água pode ser realizada em diversos tipos de superfícies, tais como: (a) telhados de diversos materiais; (b) áreas pavimentadas; e (c) represas, etc [2]. Um parâmetro importante, que influencia diretamente o volume de água captado é o chamado Coeficiente de Runoff, também conhecido como Coeficiente de Escoamento. Este pode ser definido como o quociente entre o volume de água que escoa na superfície e o total precipitado [1] (Tabela 1).

Tabela 1 - Coeficiente de Runoff médios para superfícies de cobertura

\begin{tabular}{|c|c|}
\hline Material & Coeficiente de Runof \\
\hline Telhas cerâmicas & 0,8 a 0,9 \\
\hline Telhas esmaltadas & 0,9 a 0,95 \\
\hline Telhas corrugadas de material & 0,8 a 0,9 \\
\hline Cimento amianto & 0,8 a 0,9 \\
\hline Plástico & 0,9 a 0,95 \\
\hline
\end{tabular}

Fonte: [1]

Torna-se necessário, no entanto, destacar que os estudos sobre aproveitamento de águas pluviais em fachadas são relativamente recentes e, sendo assim, as estimativas do coeficiente de Runoff para este elemento ainda não são amplamente conclusivas. Destaca-se a existência de estudos que conseguiram desenvolver, para o caso de bacias hidrográficas, fórmulas que permitissem calcular o coeficiente de Runoff através de alguns parâmetros [1]. Um exemplo deste tipo é o cálculo do coeficiente de escoamento (C) a partir da porcentagem da Área Impermeável $(\mathrm{Al})$ da bacia através da Equação 1:C=0,05 + 0,009 x Al.

\subsection{Fachadas para Captação}

A partir do entendimento da influência do material da superfície das fachadas no coeficiente de escoamento, faz-se necessário, analisar a composição das fachadas. Ao atingir uma superfície, a água precipitada pode infiltrar ou escoar superficialmente [5]. Neste trabalho serão estudas as taxas de absorção dos revestimentos: (1) argamassado com pinturas e (2) cerâmico.

A absorção dos revestimentos em argamassa é uma característica do estado endurecido que apenas sofre influência dos vazios capilares, não tendo relação com a porosidade total. Poros capilares são provenientes da reação de hidratação do cimento, tendo sua elaboração, altamente atrelada à relação água/cimento [6]. Tendo em vista a influência da relação água/cimento na taxa de absorção de água das argamassas, sabe-se que seu valor irá depender, dentre outros fatores, da condição de exposição do elemento.

Além disso, entendendo que, em muitos casos, os revestimentos argamassados são protegidos por camadas de tinta, torna-se importante conhecer a taxa de absorção deste último material, por perceber que, de modo geral, a camada 
de tinta será utilizada para proteger as argamassas de revestimento das intempéries, e portanto, estará maior contato com as águas de chuva [7]. A Tabela 2 apresenta os valores em percentual da Água Absorvida (AA) a partir dos ensaios realizados em dois diferentes laboratórios.

Tabela 2. Percentuais de Água Absorvida pela tinta

\begin{tabular}{|c|c|c|}
\hline Laboratório A & Laboratório B & Média dos Laboratórios \\
\hline $10,0 \%$ & $6,5 \%$ & $8,25 \%$ \\
\hline
\end{tabular}

Fonte: adaptado [7]

A absorção de água é uma propriedade dos materiais cerâmico e relaciona-se de forma direta com sua porosidade. A absorção de água dos revestimentos cerâmicos pode variar do quase zero para o caso dos porcelanatos chegando a mais de $10 \%$ de absorção para azulejos porosos [9]. De acordo com níveis de absorção de água, as placas cerâmicas podem ser classificadas segundo a Tabela 3 [10].

Tabela 3. Classificação das placas cerâmicas segundo sua absorção

\begin{tabular}{|c|c|l|}
\hline Tipo & Absorção & Resistência mecânica \\
\hline Porcelanatos & baixa & alta (BI a - de 0 a $0,5 \%)$ \\
\hline Grês & baixa & alta (BI b - de 0,5 a $3 \%)$ \\
\hline Semi-Grês & média & média (BII a - de 3 a $6 \%)$ \\
\hline Semi-Porosos & alta absorção & baixa (BII b - de 6 a $10 \%)$ \\
\hline Porosos & alta absorção & baixa (BIII - acima de $10 \%)$ \\
\hline
\end{tabular}

Fonte: [10]

\section{METODOLOGIA}

A metodologia adotada neste trabalho foi um estudo de caso o qual objetivou analisar a capacidade de captação de água de chuva através das fachadas de uma edificação vertical de quatro pavimentos, com $900 \mathrm{~m}^{2}$ de área de fachada (Tabela 4). Para tal, selecionou-se dois tipos de revestimentos mais comuns encontrados no Brasil, quais sejam: o revestimento argamassado com pintura e o revestimento cerâmico. Para a caracterização do empreendimento foi utilizada como fonte de evidencia a análise do projeto arquitetônico e estrutural do esmo. O levantamento do número total da população residente foi realizado por contagem direta, a demanda por água de chuva foi calculada a partir de estimativas adaptadas pelo autor, segundo a realidade da edificação e com base na Tabela 3 e a área total da fachada foi medida em campo, removendo-se os vãos abertos (esquadrias e outros elementos vazados).

Tabela 4. Características da edificação estudada

\begin{tabular}{|l|r|r|}
\hline \multicolumn{1}{|c|}{ Dados } & \multicolumn{1}{c|}{ Valores } & \multicolumn{1}{c|}{ Unidades } \\
\hline População & 53 & pessoas \\
Area de captação Total* & 900 & m2 \\
Número de dias no mês & 31 & dias \\
Demanda por água de chuva per capita - diária & 102,00 & litros/pessoa.dia \\
Demanda total por água de chuva - diária & $5.406,00$ & litros/dia \\
Demanda total por água de chuva - mensal & $167.586,00$ & litros/mês \\
\hline
\end{tabular}

* A área de captação total leva em consideração as fachadas frontal, laterais e de fundo. 
Para verificar os benefícios obtidos com esta forma de captação, necessitou-se realizar cálculos referentes aos fatores que influenciavam diretamente a análise da captação de água de chuva. As fórmulas utilizadas são apresentadas na Tabela 5.

Tabela 5. Fórmulas utilizadas nos cálculos

\begin{tabular}{|c|c|c|c|}
\hline Equação & Índice & Fórmula & Variáveis \\
\hline 1 & $\begin{array}{l}\text { Coeficiente de } \\
\text { Escoamento }(C)\end{array}$ & $C=0,05+0,009 \times A I$ & $\begin{array}{l}C=\text { Coeficiente de Escoamento }(\text { Runoff }) \\
A I=\text { Área Impermeável }\left(m^{2}\right)\end{array}$ \\
\hline 2 & $\begin{array}{l}\text { Área } \\
\text { Impermeável da } \\
\text { Fachada }\end{array}$ & $A I=A t f-T a a X A t f$ & $\begin{array}{l}\text { AI = Área Impermeável }\left(\mathrm{m}^{2}\right) \\
\text { Atf }=\text { Área Total da Fachada }\left(\mathrm{m}^{2}\right) \\
\text { Taa = Taxa de absorção }(\%)-\text { Relativa ao } \\
\text { Material }\end{array}$ \\
\hline 3 & $\begin{array}{l}\text { Volume Captado } \\
\text { Mensal (Vcap) }\end{array}$ & $V c a p=C \times A \times I m$ & $\begin{array}{l}\text { Vcap }=\text { Volume captado Mensal }(\mathrm{L} / \mathrm{mês}) \\
C=\text { Coeficiente de Runoff (para cada tipo de } \\
\text { fachada) } \\
\text { AI = Area de Captação }\left(\mathrm{m}^{2}\right) \\
\text { Im }=\text { Precipitação mensal }(\mathrm{mm} / \mathrm{mês})\end{array}$ \\
\hline 4 & $\begin{array}{l}\text { Volume Captado } \\
\text { Diário (Vcapd) }\end{array}$ & $V c a p d=C \times A \times I d$ & $\begin{array}{l}\text { Vcapd = Volume captado diário (L/dia) } \\
C=\text { Coeficiente de Runoff (para cada tipo de } \\
\text { fachada) } \\
A=\text { Area de Captação }(\mathrm{m} 2) \\
I d=\text { Precipitação diária }(\mathrm{mm} / \text { dia })\end{array}$ \\
\hline 5 & $\begin{array}{l}\text { Taxa de } \\
\text { Atendimento } \\
\text { Mensal (\%Tam) }\end{array}$ & $\begin{array}{l}\% \operatorname{Tam}= \\
(\text { Vcap } / \text { Vdemm }) \times 100\end{array}$ & $\begin{array}{l}\% \text { Tam }=\text { Taxa de atendimento mensal }(\%) \\
\text { Vcap }=\text { Volume captado mensal }(L / m e ̂ s) \\
\text { Vdemm }=\text { Volume de água de chuva demandado } \\
\text { mensal (L/mês })\end{array}$ \\
\hline 6 & $\begin{array}{l}\text { Taxa de } \\
\text { Atendimento } \\
\text { Diária }(\% \text { Tad })\end{array}$ & $\begin{array}{l}\% \operatorname{Tad}= \\
(\text { Vcapd/Vdemd }) \times 100\end{array}$ & $\begin{array}{l}\% \text { Tad }=\text { Taxa de atendimento diária }(\%) \\
\text { Vcapd }=\text { Volume captado diário }(\text { L/dia }) \\
\text { Vdemd }=\text { Volume de água de chuva demandado } \\
\text { diário }(\text { L/dia })\end{array}$ \\
\hline
\end{tabular}

Este modelo permite ao usuário utilizar como informações de entrada: (1) demanda mensal e diária; (2) serie de precipitação mensal e diária; (3) área de captação, que para este estudo é igual a área impermeável (AI); e (4) coeficiente de escoamento, para obter respostas em relação a taxa de atendimento à demanda diária e mensal para diferentes meses do ano. A Tabela 6 apresenta a demanda residencial de água não potável [1].

Tabela 6. Demanda residencial de água não potável

\begin{tabular}{|l|r|r|}
\hline \multicolumn{1}{|c|}{ Demanda } & Faixa & \multicolumn{1}{c|}{ Unidade } \\
\hline Interna & & L/descarga \\
Vaso sanitário - volume & 6 a 15 & 4 a 6 \\
Vaso sanitário - frequência & 100 a 200 & Descarga/hab/dia \\
Máquina de lavar roupa - volume & 0,2 a 0,3 & L/ciclo \\
Máquina de lavar roupa - frequência & & Ciclo/hab/dia \\
Externa & 2 & L/dia/m2 \\
Regar jardim - volume & 8 a 12 & vezes $/$ mês \\
Regar jardim - frequência & 80 a 150 & L/lavagem $/$ carro \\
Lavagem de carro - volume & Lavagem $/$ mês \\
Lavagem de carro - frequência & & Lavem \\
\hline
\end{tabular}


Em relação aos parâmetros de entrada, pela falta de valores referentes ao coeficiente de escoamento das fachadas, para efeitos ilustrativos de cálculo, utilizouse a Equação 1 da Tabela 5 em fachadas com revestimentos argamassado com pintura e cerâmico. Para isso, considerou-se como área impermeável, a área total da fachada menos a porcentagem da área da fachada que irá absorver a água precipitada de acordo com a taxa de absorção de cada material. Este cálculo é demonstrado na Equação 2 da Tabela 5.

Para o revestimento argamassado com pintura foi utilizado, como taxa de absorção de $8,25 \%$. Já para o revestimento cerâmico, foi utilizado o valor de $0,5 \%$ (porcelanatos) para taxa de absorção, visto que são tipos de placas cerâmicas usualmente aplicadas em fachadas. Os valores de coeficientes de escoamento calculados para cada tipo de revestimento são apresentados na Tabela 7.

Tabela 7. Coeficiente de Escoamento para cada Tipo de Revestimento

\begin{tabular}{|c|c|c|}
\hline Tipo de Revestimento & Taxa de absorção & Coeficiente de Escoamento (C) \\
\hline Argamassado com Pintura & $8,25 \%$ & 7,48 \\
\hline Cerâmico & $0,5 \%$ & 8,11 \\
\hline
\end{tabular}

No tocante a série de precipitação, para o presente estudo, foram utilizados, na análise da capacidade de captação, os índices de precipitação do mês mais chuvoso e do mês mais seco da cidade de Salvador no ano de 2017, estes são: maio e janeiro respectivamente [11]. Os valores dos índices pluviométricos mensais dos meses de janeiro/2017 e maio/2017 pode ser visto na Figura 1.

Figura 1. Índices Pluviométricos de Salvador/BA

Instituto Nacional de Meteorologia - INMET

Chuva Acumulada Mensal X Chuva (Normal Climatológica 61-90) SALVADOR (ONDINA) (BA) - Para o Ano: 2017

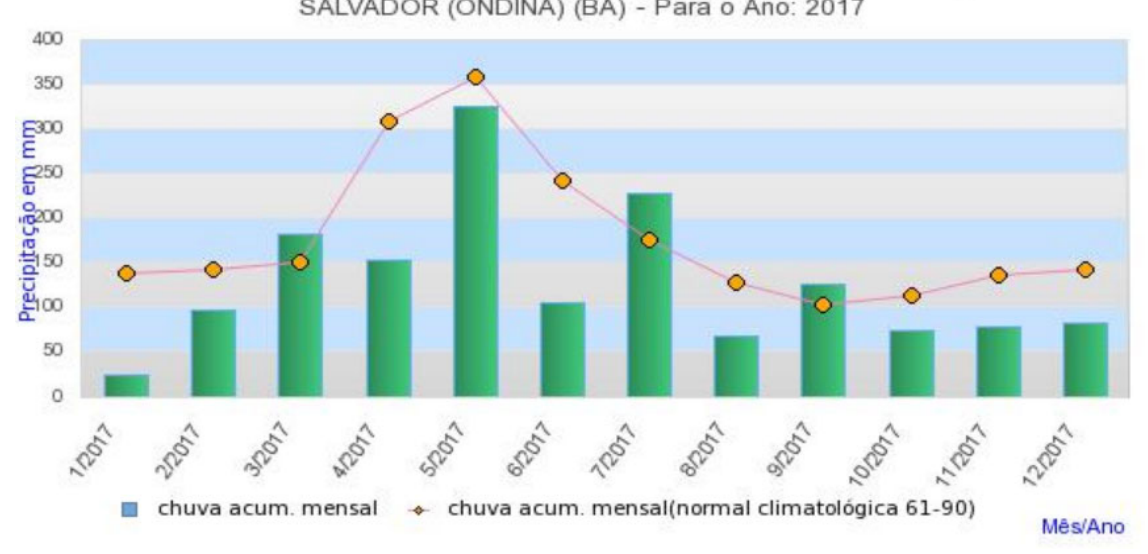

Fonte: [10]

\section{RESULTADOS E DISCUSSÃO}

Os valores dos cálculos da Economia Mensal de Água (\%Eco) para os dois tipos de revestimentos, nos meses estudados, são apresentadas na Tabela 8. 
Tabela 8. Porcentagem de Água Economizada nos meses de janeiro e maio

\begin{tabular}{|c|r|r|r|r|}
\cline { 2 - 5 } \multicolumn{1}{c|}{} & \multicolumn{2}{c|}{ Argamassa com Pintura } & \multicolumn{2}{c|}{ Cerâmica } \\
\cline { 2 - 5 } \multicolumn{1}{c|}{} & jan/17 & mai/17 & jan/17 & mai/17 \\
\hline Vcap $(\mathrm{L})$ & $160.894,8$ & $2.275 .416,0$ & $174.446,1$ & $2.467 .062,0$ \\
\hline Vdeman $(\mathrm{L})$ & $167.586,0$ & $167.586,0$ & $167.586,0$ & $167.586,0$ \\
\hline \%Eco & $96 \%$ & $1358 \%$ & $104 \%$ & $1472 \%$ \\
\hline
\end{tabular}

Percebe-se que para a edificação em estudo, em ambos os revestimentos, e considerando tanto o mês mais seco quanto o mais chuvoso, a captação de água de chuva através das fachadas se mostra uma alternativa vantajosa visto que o menor valor de porcentagem economizada no mês foi de $96 \%$ da demanda de água para fins não potáveis. Entendendo que este valor representa o mês mais seco do ano na cidade de Salvador/BA, este método se mostra passível de ser utilizado nos demais meses.

As altas porcentagens de economia encontradas no mês de maio, se justificam pelo alto índice de precipitação que este mês possui, aliado a grande área de captação das fachadas. Quanto ao tipo de revestimento, a fachada com revestimento cerâmico apresentou ligeira vantagem quando comparada com as de pintura, embora ambas possuam boa capacidade de captação. Esta vantagem se deve pelo maior coeficiente de escoamento calculado, pois a área de contribuição e os índices de chuva são os mesmos.

\section{CONCLUSÃO}

O objetivo deste trabalho visou avaliar o potencial de captação de águas pluviais pelas fachadas de um edifício para fins não potáveis. Pôde-se perceber que o volume de captação é significativo em suprir a demanda de água para fins não potáveis, nos meses mais secos, e pode servir para fins de armazenagem, nos meses mais chuvosos, com o propósito de garantir a disponibilidade de água ao longo do ano, mesmo em extensos períodos sem ocorrência de chuva. Isto foi possível, dentre outros fatores, pelo tamanho da área de captação que as fachadas possuem, sendo consideráveis no intuito de aumentar o volume captado. Além disso, o estudo demonstrou que a captação de água de chuva é possível para os dois tipos mais comuns de revestimentos de fachada encontrados na cidade de Salvador/BA, quais sejam: argamassados com pintura e cerâmico.

É bem verdade que este estudo não considerou a parcela de água precipitada que realmente escoa pela fachada, proveniente das chuvas dirigidas, assim como o real valor do coeficiente de escoamento (Runoff) que cada tipo de fachada apresenta, uma vez que a obtenção destes valores foram pontos de dificuldades encontrados. No entanto este trabalho não tem a pretensão de finalizar os estudos acerca do aproveitamento de água de chuva pelas fachadas, e sim, demonstrar a importância e relevância que esta forma de captação pode ter principalmente para suprir as necessidades em períodos de estiagem de chuva, cada vez mais comuns em todo o planeta. Além disso, toda ação que tem potencial de contribuir com a economia de 
água deve ser vista com bons olhos, pois este recurso vem se tornando cada vez mais escasso.

Sugere-se, dessa forma, para estudos futuros, a estimativa correta do coeficiente de Runoff dos diversos tipos de materiais que compõe as fachadas, assim como o cálculo da capacidade de captação levando em conta a chuva dirigida. Ademais, a criação de normas que tragam diretrizes para captação de água, não só nas fachadas, mas também em outros ambientes com grandes áreas de captação, tais como quadras esportivas, praças e decks de piscina, entre outros, podem promover o aumento desta forma de captação e, consequentemente melhorar a relação do ser humano com este bem precioso que é a água. Deve-se atentar também a forma de tratamento das águas captadas proveniente destes ambientes, pois as sujeiras existentes nestes não são as mesmas encontradas em outras áreas destinadas a captação e reuso da água.

\section{REFERÊNCIAS}

${ }^{1}$ TOMAZ, P. Curso de Manejo de águas pluviais. Capítulo 2. Método Racional. São Paulo. 2013.

${ }^{2}$ SILVA, Â. M. de A. Mercado de residências de alto padrão como instrumento para inserção de especificações ambientais: captação predial de água de chuva. Dissertação (Mestrado) - Universidade Federal da Bahia. Escola Politécnica. Salvador-BA, 2011.

${ }^{3}$ COHIM, E.; GARCIA, A. P.; KIPERSTOK, A. Captação de água de chuva no meio urbano para usos não potáveis. $6^{\circ}$ Simpósio Brasileiro de Captação e Manejo de Água de Chuva. Belo Horizonte - MG. Julho de 2007.

${ }^{4}$ CALVIÑO, G. Projeto de captação de água pluvial deve estar alinhado com previsão de demanda do condomínio. Revista Construção Mercado. PINI. Maio. 2016

${ }^{5}$ CARVAlhO, D. F. de; SILVA, L. D. B. da. Escoamento superficial. Capítulo 7. Apostila de Hidrologia. Universidade Federal Rural do Rio de Janeiro. 2006. Disponível em: http://www.ufrrj.br/institutos/it/deng/leonardo/downloads/APOSTILA/HIDRO-Cap7-ES.pdf. Acesso em: 09 de janeiro de 2018.

${ }^{6}$ ZANELATO, E. B. Influência do Chapisco na Resistência de Aderência à Tração de Revestimentos de Argamassa em Blocos Cerâmicos. Dissertação (Mestrado). Universidade Estadual do Norte Fluminense Darcy Ribeiro Uenf. Campos dos Goytacazes - Rj. 2015.

${ }^{7}$ AMARO, Mariana Fonseca. Estudo Comparativo de Tintas para Fachadas. Volume I. Dissertação (Mestrado em Engenharia Química). Instituto Superior Técnico. Universidade Técnica de Lisboa. Lisboa. 2007.

${ }^{8}$ TOLEDO, L. B. F. Patologia em revestimentos cerâmicos de fachadas de edifícios estudo regionalizado para a cidade de Divinópolis - MG. Dissertação (Mestrado). UNIVERSIDADE FEDERAL DE MINAS GERAIS. Belo Horizonte. 2007.

${ }^{9}$ ArqTeMa: Arquitetura, Tecnologia e Materiais. Características dos Revestimentos Cerâmicos. Disponível em: http://www.iau.usp.br/pesquisa/grupos/arqtema/ceramica/principal4.htm. Acesso em 09 de janeiro de 2018. USP.

${ }^{10}$ INMETRO - Instituto Nacional de Metrologia, Qualidade e Tecnologia. Informação ao Consumidor. Disponível em: http://www.inmetro.gov.br/consumidor/produtos/revestimentos.asp. Acesso em 11 de janeiro de 2018.

${ }^{11}$ INMET - Instituto Nacional de Meteorologia. Gráficos de Precipitação. Disponível em: http://www.inmet.gov.br/portal/index.php?r=tempo/graficos. Acesso em: 11 de janeiro de 2018.

Associação Brasileira de Normas Técnicas. NBR 13529: Revestimentos de paredes e tetos de argamassa inorgânicas. Rio de Janeiro, 2013. 